\title{
Squamous cell carcinoma of the toenail bed: a case report
}

\author{
Reza Yaghoobi ${ }^{1}$, Farzaneh Alamshahi ${ }^{2 *}$, Nooshin Bagherani ${ }^{3}$, Mahdi Saboktakin Rizi ${ }^{4}$ and Nader Paziar ${ }^{5}$ \\ ${ }^{1}$ Professor of Dermatology, Department of Dermatology, Ahvaz Jundihapour University of Medical Sciences, Ahvaz, Iran \\ ${ }^{2}$ Resident of Dermatology, Department of Dermatology, Ahvaz Jundishapour University of Medical Sciences, Ahvaz, Iran \\ ${ }^{3}$ Dermatologist, Taha Physicians' Building, Khoramshahr, Khuzestan Province, Iran \\ ${ }^{4}$ Dermatologist, Iran \\ ${ }^{5}$ Dermatologist, Department of Dermatology, Ahvaz Jundishapour University of Medical Sciences, Ahvaz, Iran
}

\begin{abstract}
Subungual Squamous Cell Carcinoma (SCC) is the most common malignancy affecting the nail bed. About 150 cases of subungual SCC have been reported in the literature. It usually involves the thumb, the index finger and only rarely, the toes.
\end{abstract}

Subungual SCC runs an indolent course and may present with minimal symptoms. Diagnostic confusion emerges because many chronic lesions of the nail bed may be clinically similar to SCC.

Although SCC of the nail bed is considered a low-grade malignancy, bone invasion and metastasis to the regional lymph nodes may occur.

Herein, we reported a case of subungual toenail SCC with bone involvement and a 6-year delay between its appearance and diagnosis.

\section{Introduction}

Squamous- celled epithelioma (squamous cell carcinoma) of the nail bed or sulcus is a well-known but uncommon type of the neoplasm, example of which have been recorded by Sigel (1937), Bunnell (1944), and Willis (1948) [1]. Some literature described its first reported cases by Velpeau in 1850 [2]. However, up to 1948, some fifteen cases involving the hand have been recorded in the literature, mostly in men over the age of sixty years [1]. About 150 cases have been reported in the literature $[2,3]$.

Although SCC of the nail bed is a rare disease, it is the most commonly observed malignant subungual tumor. It usually involves the thumb, the index finger and only rarely, the toes [3].

Subungual SCC runs an indolent course and may present with minimal symptoms [4]. Diagnostic confusion emerges because many chronic lesions of the nail bed may be clinically similar to SCC $[3,5]$.

Although SCC of the nail bed is considered a low-grade malignancy, bone invasion and metastasis to the regional lymph nodes may occur. Fatal dissemination is only very occasionally reported [3].

Herein, we reported a case of subungual toenail SCC with bone involvement and a 6-year delay between its appearance and diagnosis.

\section{Case presentation}

A 70-year-old man presented with a 6-year history of a lesion affecting his left first toenail (Figure 1). His problem has begun after a blunt trauma as a painful and ulcerated lesion. Several days after trauma, its nail plate had shed, and since that time it has not grown. During these years, his lesion has become larger without any history of complete resolution. It has become infected since some months ago.

Examination revealed a necrotic and ulcerated lesion at bed of the left first toe nail, $2 \times 2.5 \mathrm{~cm}$ in diameter. Systemic examination was unremarkable.

Clinically with considering subungual melanoma and SCC as differential diagnoses, a biopsy was performed.

The histopathological findings were consistent with welldifferentiated SCC (Figure 2 and 3). The findings of laboratory tests and chest X-Ray were normal. Left foot radiography showed bone invasion of the first phalange (Figure 4).

After the diagnosis confirmation, because of the bone involvement, the patient underwent amputation at the level of the metatarsophalyngeal.

\section{Discussion}

The vast majority of nail bed conditions treated by clinicians are benign. Although rare, subungual SCC is the most common malignancy affecting the nail bed [4]. The age of patients in its reported cases ranges from 20 to 90 years, with $45 \%$ of cases affecting individuals aged between 50 and 69 years [2]. It is prevalent in males after the fifth decade of life [3]. Eighty-four percent of subungual SCC occurs in the fingers, the remaining in the toes [6]. The majority of subungual SCC in the fingers occurs in the thumb (44\%); and those in the toes affect the great toe predominantly (64\%) [6]. The disease can arise from the nail bed, nail matrix, nail groove or lateral folds [3].

Correspondence to: Dr. Farzaneh Alamshahi, Emam Khomeini Hospital, 61335, Ahvaz, Iran P.O.Box: 61335 - 4156, Fax: +98- 611-3381110; E-mail: dr.alamshahi@yahoo.com

Key words: subungual, toenail, squamous cell carcinoma

Received: August 26, 2015; Accepted: October 03, 2015; Published: October 07,2015 


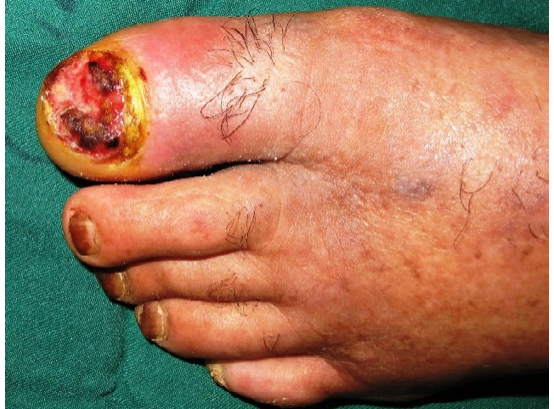

Figure 1. A 70-year old man presented with a mass lesion in the first toenail bed.

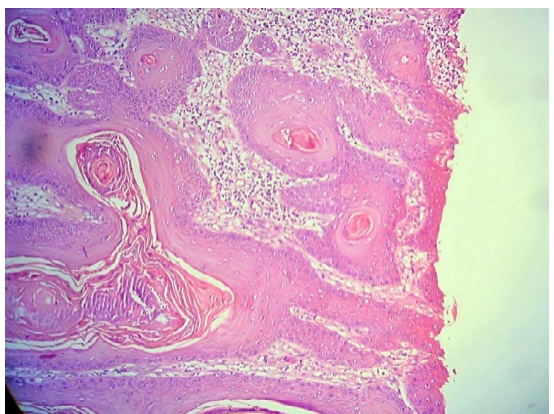

Figure 2. Histopathological view of the lesion in Figure 1 (Hematoxylin ad Eosin, $\times 10)$.

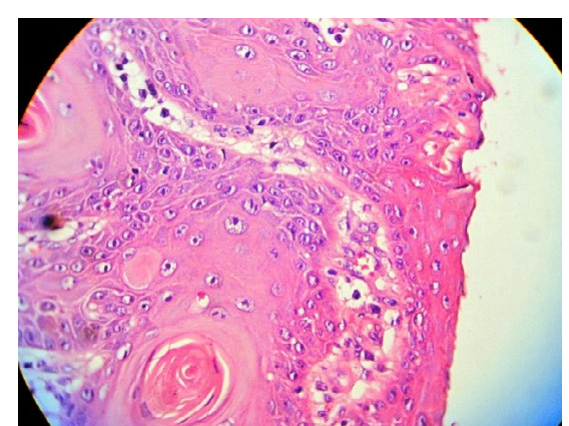

Figure 3. Pathological view of the same section as shown in Figure 2 (Hematoxylin \&Eosin, $\times 40$ ).

This slow-growing tumor nearly always presents as an infection at the initial clinical presentation, followed by nail plate deformity and throbbing pain [5]. Over all, clinical features are not specific [3], and presenting symptoms can range from deceptively benign nail plate dyschromia, onycholysis and paronychia, to bleeding, frank ulceration and distant metastases [4]. Thus, as signs and symptoms may be deceiving, anything up to 18 years may be necessary to complete a diagnosis with on average, a 4-year delay, with a range of 1-14 years [3]. In some cases, it may not be detected for up to 40 years [4]. However, the presence of a rapidly growing tumor usually alerts the physician and the patient of the possibility of malignancy [2]. In our case a 6 year delay was appeared to exist between appearance and diagnosis of the tumor.

While the precise aetiology of subungual SCC remains to be determined [4], predisposing factors for this include chronic pronychia $[1,6]$, trauma [1,3-6], chronic infection [1,3,7], radiation exposure [3-7], arsenic exposure [3,5,7], actinic damage [3-5], dyskeratosis congenital [5], congenital ectodermal dysplasia [4,6], immunosuppression [4], tar, minerals, sodium hypochlorite [7], and previous human papillomavirus (HPV) infection [3-6,8]. Mounting evidence suggest that specific HPV subtypes may be involved in the pathogenesis of digital and periungual SCCs. Specifically, HPV 16 and related types have been implicated [8]. In another study, HPV DNA was present in $80 \%$ of cases of subungual SCC carcinoma by dot-blot analysis of frozen tissue and $60 \%$ were related to HPV 16 [6]. Nasca et al. reported that unlike Bowen's disease and SCC of the fingernails, a causative role of HPV infection in the development of in situ and invasive subungual SCC of the toes seems unlikely [9]. However, association of HPV with SCC in locations on the exposed skin apart from the distal digits is rare [8].

Subungual SCC must be distinguished from following conditions: malignant melanoma of the nail [1,2,7], melanocytic naevi [4,7], chronic paronychia [1-4,7], chronic eczema [7], onychomycosis [2- 4], warts $[2-4,7]$, nail deformity [3], pyogenic granuloma [3,7], implantation dermoid cyst, subungual fibroma [6], glomus tumor [4,6,7], giant cell tumor of tendon sheath [6], subungual keratoacanthoma $[4,6]$, mucous cyst [6], subungual exostosis, chronic osteomyelitis , traumatic dyschromia of the nail plate [3], syphilitic chancre, subungual hematoma and metastases [7] especially from bronchial carcinoma to the phalanges of the hand [1].

The distinction between invasive and in situ SCC is frequently difficult, given the complex three-dimensional structure of subungual and periungual tissue. Thus, even if the diagnostic biopsy shows in situ SCC, it is often appropriate to treat as if there was an invasive component, with amputation of the digit at the appropriate joint [2].

Dermoscopy of the nail apparatus has been shown to be increasingly helpful in differentiating between pigmentation from non-melanocytic origin such as subungual haematoma, bacterial or fungal infections, and the melanocytic lesions of benign naevi, racial pigmentation and melanoma [4].

Up to 1993, no metastases had been reported in the cases of subungual SCC [5]. More recent review has shown that bone involvement is seen in fewer than $20 \%$ of cases of subungual SCC, and metastases are even rarer (1.7\%) [6]. In some literatures, bony invasions have been shown in $55 \%$ of cases $[4,10]$. Alam et al. reported metasases

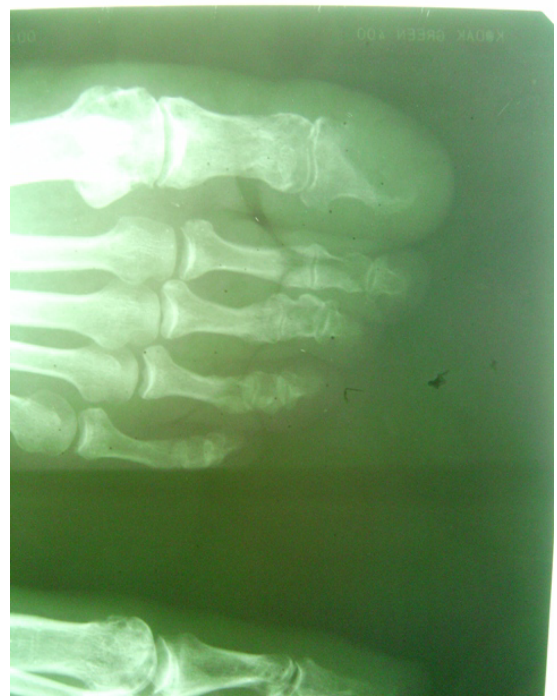

Figure 4. Bone involvement in subungual squamous cell carcinoma in the case showed in Figure 1. 
in $3 \%$ of the cases with digital SCC [8]. Bone invasion may not be a risk factor for lymphatic spread [2]. Disseminated metastases have rarely been reported, although they are more frequent in relatively young patients and are influenced by the histological degree of differentiation and the depth of invasion of the primary tumor. Disseminated metastases of SCC are associated with a high mortality rate. A 10- year follow-up is recommended, as lymph node or distant metastases may appear many years after treatment [3].

SCC is considered a low-grade malignant tumor [3,7], characterized by slow growth and little pain. Treatment depends on the extension of the tumor and may vary from wide local excision to amputation of the distal phalanx and lymph node dissection in the case of metastasis [3]. Some authors support distal amputation or disarticulation [7]. The use of Moh's micrographic surgery has been reported for the treatment of the nail unit SCC, which can avoid the need for amputation whilst ensuring complete tumor removal [2].

\section{References}

1. Ellis VH (1948) Squamous-celled carcinoma of the nail bed. J Bone Joint Surg 4: 656658. [Crossref]
2. Tabesh H, Wilson S, Leonard AG (2003) Subungual squamous cell carcinoma. Eur J plast Surg 26: 258-259.

3. Virgili A, Zampino MR, Bacilieri S, Bettoli V, Chiarelli (2001) Subungual squamous cell carcinoma of the nail bed: a rare disease or only misdiagnosed? Acta Derm Venereol 81: 306-307.

4. Oon HH, Kumarasinghe SPW (2008) Subungual squamous cell carcinoma masquerading as a melanotic macule. Singapore Med J 49: 76-77. [Crossref]

5. Conill C, Verger E, Vilalta A, Palou J (1993) Case report: squamous cell carcinoma of the nail bed. Br JR 66: 163-164

6. Bui-Mansfield LT, Pulcini JP, Rose S (2005) Subungual squamous cell carcinoma of the finger. AJR 185: 174-175.

7. Porembski MA, Rayan GM (2007) Subungual carcinomas in multiple digits. $J$ Hand Surg 5: 547-549. [Crossref]

8. Alam M, Caldwell JB, Eliezri YD (2003) Human papillomavirus- associated digital squamous cell carcinoma: literature review and report of 21 new cases. $\mathrm{J} \mathrm{Am} \mathrm{Acad}$ Dermatol 48: 385-393. [Crossref]

9. Nasca MR, Innocenzi D, Micali G (2004) Subungual squamous cell carcinoma of the toe: report on three cases. J Orthop Surg 12: 248-252. [Crossref]

10. Lumpkin LR $3^{\text {rd }}$, Rosen T, Tschen JA (1984) Subungual squamous cell carcinoma. $J$ Am Acad Dermatol 11: 735-738.

Copyright: (C2015 Yaghoobi R. This is an open-access article distributed under the terms of the Creative Commons Attribution License, which permits unrestricted use, distribution, and reproduction in any medium, provided the original author and source are credited. 